\title{
Bypass Budget
}

National Cancer Institute

\section{Source}

National Cancer Institute. Bypass Budget. NCl Thesaurus. Code C19714.

The Bypass Budget, which is specified in the National Cancer Act, describes the NCl's priorities and planning and guides $\mathrm{NCl}$ efforts in discharging its responsibilities as mandated. 